\title{
Biomarkers for EMT and MET in breast cancer: An update (Review)
}

\author{
FEI LIU ${ }^{1,2}$, LI-NA GU ${ }^{2}$, BAO-EN SHAN ${ }^{1,2}$, CUI-ZHI GENG ${ }^{3}$ and MEI-XIANG SANG ${ }^{1,2}$ \\ ${ }^{1}$ Tumor Research Institute; ${ }^{2}$ Research Center; ${ }^{3}$ Breast Center, \\ The Fourth Hospital of Hebei Medical University, Shijiazhuang, Hebei 050017, P.R. China
}

Received May 19, 2015; Accepted September 29, 2016

DOI: $10.3892 / \mathrm{ol} .2016 .5369$

\begin{abstract}
Metastasis and recurrence are the leading cause of mortality due to breast cancer, but the underlying mechanisms are still poorly understood. Understanding the breast cancer metastasis mechanism is important for early diagnosis and treatment of breast cancer. The seeding and growth of breast cancer cells at sites distinct from the primary tumor is a complex and multistage process. Recently, it has been reported that the epithelial-mesenchymal transition (EMT) and the mesenchymal-epithelial transition (MET) are the main mechanisms for breast cancer metastasis. During EMT, carcinoma cells shed their differentiated epithelial characteristics, including cell-cell adhesion, polarity and lack of motility, and acquire mesenchymal traits, including motility and invasiveness. This review has summarized the studies of known EMT biomarkers in the context of breast cancer progression. These biomarkers include EMT-related genes, proteins, microRNAs and kinases. In general, the findings of these studies suggest that EMT markers are associated with the invasion and metastasis of breast cancer. Further studies on the link between EMT markers and breast cancer will contribute to identify biomarkers for predicting early breast cancer metastasis as well as to provide new ideas for the treatment of breast cancer.
\end{abstract}

\section{Contents}

1. Overview of EMT and MET

2. Biomarkers for EMT in breast cancer

3. EMT transcription factors in breast cancer

4. EMT-related miRNAs in breast cancer

5. EMT-related protein kinase in breast cancer

6. Conclusion

Correspondence to: Professor Mei-Xiang Sang, Tumor Research Institute, The Fourth Hospital of Hebei Medical University, 12 Jiankang Road, Shijiazhuang, Hebei 050017, P.R. China E-mail: mxsang@hotmail.com

Key words: breast cancer, epithelial-mesenchymal transition, mesenchymal-epithelial transition, biomarker, microRNA, protein kinase

\section{Overview of EMT and MET}

Breast cancer is the most commonly diagnosed cancer $(1,2)$. It is also the second leading cause of cancer-related mortalities in females. Among these patients, more than $90 \%$ of breast cancer-related mortalities are caused not by the primary tumor, but by its metastases at distant sites (2). In 6-10\% of breast cancer diagnoses, cancer has already metastasized to other parts of the body, and $\sim 30 \%$ of patients with early-stage breast cancer have a metastatic or recurrent disease (3). Understanding the breast cancer metastasis mechanism is important for early diagnosis and treatment of breast cancer. The precise mechanisms that are involved in the transition of the subset of non-invasive tumor cells into cells with metastatic potential are still not well understood. However, accumulating evidence suggests that an epithelial-mesenchymal transition (EMT)-like process is one of the main mechanisms involved in breast cancer metastasis (4).

EMT describes a process in which cells lose epithelial traits and gain mesenchymal characteristics. EMT is characterized by loss of cell adhesion and phenotypic change from typical cuboidal to an elongated spindle shape, leading to enhanced migratory capacity (5). In the early stage of tumor metastasis (Fig. 1), cancer cells from the primary tumor could acquire invasive properties and gain access to the blood or lymphatic vascular systems as circulating tumor cells (CTCs) $(6,7)$. This procedure is aided by neo-angiogenesis and remodeling of the basement membrane (8-10). In the bloodstream and lymphatic vessels, CTCs are capable of surviving and eventually reach distant secondary sites, including the bone, lungs, liver and brain. This process is accomplished mainly by the mesenchymal-epithelial transition (MET), which is a process opposite to the initial EMT at the primary tumor site, and is considered to contribute substantially to the colonization of CTCs into metastatic tumors at the secondary site (11-14). Such dynamic EMT/MET state transitions may play a critical role during tumor metastasis.

The purpose of this review is to present the growing evidence (4) that EMT plays a significant role in the invasion and metastasis of breast cancer. Numerous EMT-related genes, proteins, microRNAs (miRNAs or miRs) and kinases contribute to EMT, and they are associated with breast cancer invasion and metastasis. However, there is no systematic summary for the association between EMT markers and 
breast cancer. In the present study, the association between EMT markers and breast cancer invasion and metastasis will be summarized.

\section{Biomarkers for EMT in breast cancer}

A variety of biomarkers have been used to demonstrate EMT in breast cancer (Fig. 2). Here, we examine various of the most common markers, some of which are acquired, while some of which are attenuated, during the transition.

E-cadherin is a calcium-dependent cell-surface protein that facilitates adhesion between epithelial cells (15). E-cadherin is characterized by long cytoplasmic and extracellular domains, which create homophilic interactions between adjacent cells to facilitate adhesion (16). A changein the expression of E-cadherin is the typical epithelial cell marker of EMT (17). Suppression of E-cadherin function or expression leads to mesenchymal morphology and increased cell migration and invasion $(18,19)$ as well as metastasis (20). In breast cancer, partial or total loss of E-cadherin expression correlates with loss of differentiation characteristics, acquisition of invasiveness, increased tumor grade, metastatic behavior and poor prognosis (21-24). Furthermore, its reduced expression can also be associated with some non-lobular breast carcinomas of triple-negative phenotype such as metaplastic carcinomas $(25,26)$. Choi et al analyses revealed that the loss of E-cadherin in invasive carcinoma is greater than in pure ductal carcinoma in situ (DCIS) in basal-like subtype cancer (27). Recently, changes in the level of expression of different cadherins have been increasingly used to monitor EMT. Indeed, the cadherin switch from E-cadherin to $\mathrm{N}$-cadherin has often been used to monitor the progress of EMT during cancer progression. This switch increases cell motility and the abilities of invasion and metastasis (28). In addition, E-cadherin also plays a major role in the process of MET. In a previous study, Chao et al reported the re-expression of E-cadherin at distant metastatic tumors arising from E-cadherin-low or E-cadherin-negative primary tumors (11). The authors reported strong E-cadherin expression in $>50 \%$ of liver, brain and lung metastases originating from infiltrating ductal carcinoma of the breast (29).

Cluster of differentiation (CD) 44 is a cell-surface protein that modulates cellular signaling by forming co-receptor complexes with various receptor tyrosine kinases. It plays an important role in the metastasis of breast cancer (30). Some studies have shown an upregulation of CD44 in a metastatic cell line as compared with a non-metastatic cell line (31). There is a shift in CD44 expression from the variant isoform (CD44v) to the standard isoform (CD44s) during EMT. The splicing factor epithelial splicing regulatory protein 1 could control the CD44 isoform switch, which is critical for regulating the EMT phenotype. CD44s expression is upregulated in high-grade human breast neoplasms, and is correlated with the level of the mesenchymal marker $\mathrm{N}$-cadherin in these tumors (30).

Discoidin domain receptor 2 (DDR2) is an atypical receptor tyrosine kinase. It is the collagen-specific receptor that reflects adaptation to the altered ECM microenvironment associated with the EMT (32). In adult tissues, the expression of DDR2 is confined to subsets of fibroblasts or vascular smooth muscle cells $(33,34)$. In cancer, DDR2 facilitates prostate cancer cells to adhere to type I collagen. It plays an important role in prostate cancer bone metastasis (35). In breast cancer, DDR2 expression correlates with increased invasiveness, thus demonstrating its utility in identifying EMT (36). It has been reported that activation of the collagen I receptor DDR2 regulates Snaill protein stability by stimulating extracellular signal-regulated kinase 2 (ERK2) activity. Activated ERK2 directly phosphorylates Snaill and reduces its ubiquitination; as a result, the half-life of Snail1 increases. DDR2-mediated stabilization of Snail1 promotes breast cancer cell invasion and metastasis in vivo (37). Recent research suggests that DDR2 facilitates breast cancer cell metastasis in vivo as well as hypoxia-induced cell migration, invasion and EMT in vitro. DDR2 could be a potential target to treat breast cancer metastasis (38).

$\beta$-catenin is a cytoplasmic plaque protein that plays an important role in EMT (39). $\beta$-catenin is localized in the cell membrane of normal epithelial cells and noninvasive tumor cells. In cells undergoing EMT, $\beta$-catenin is located either in the cytoplasm or in the nucleus of the cells. $\beta$-catenin localization in the cytoplasm is reflective of its dissociation from E-cadherin (40). Subsequently, $\beta$-catenin translocates to the nucleus to promote the transcription of genes that induce EMT (41). Prasad et al provided clinical evidence to support the upregulation of $\mathrm{Wnt} / \beta$-catenin signaling in invasive ductal carcinoma of breast (42). Choi et al reported a higher expression of $\beta$-catenin in invasive carcinomas than in pure DCIS, especially in basal-like subtype breast cancers (27). Moreover, the notable reduction of $\beta$-catenin expression and $\beta$-catenin/transcription factor 4 (TCF4) transcriptional activity by $\beta$-catenin short hairpin RNAs (shRNAs) in HMLE cells expressing cyclin-dependent kinase-like 2 (CDKL2) resulted in decreased zinc finger E-box binding homeobox 1 expression level and promoter activity, as well as in increased $\mathrm{E}$-cadherin expression and redistribution from the perinuclear region to the membrane (43). This suggests that the silencing of $\beta$-catenin can reverse CDKL2-induced EMT in breast cancer.

Vimentin is an intermediate filament that is used as a marker of mesenchymal cells to distinguish them from epithelial cells (41). Vimentin is expressed at sites of cellular elongation, and is associated with a migratory phenotype. Increased vimentin expression is frequently used as an EMT marker in cancer $(44,45)$. There is a positive correlation of vimentin expression with augmented invasiveness and metastasis. In breast cancer, it was observed that Smad-interacting protein 1 (SIP1) could regulate vimentin expression in epithelial breast tumor cells, and that vimentin was distinctly related to SIP1 expression in invasive cell lines (46). These data suggest that the regulation of vimentin by SIP1 can be independent of E-cadherin expression and does not necessarily rely on the modulation of the $\beta$-catenin/TCF pathway. Nevertheless, many other indirect mechanisms could be involved (46). In addition, vimentin expression was found to be significantly higher in patients with stage IV disease, Bloom Richardson score 4 and progesterone receptor negativity. That study revealed that vimentin expression was a significant biomarker for predicting reduced disease-free survival and overall survival in breast cancer (47).

$\alpha$-smooth muscle actin ( $\alpha$-SMA) is one of the six actin family members (48). Cells expressing $\alpha$-SMA contribute 


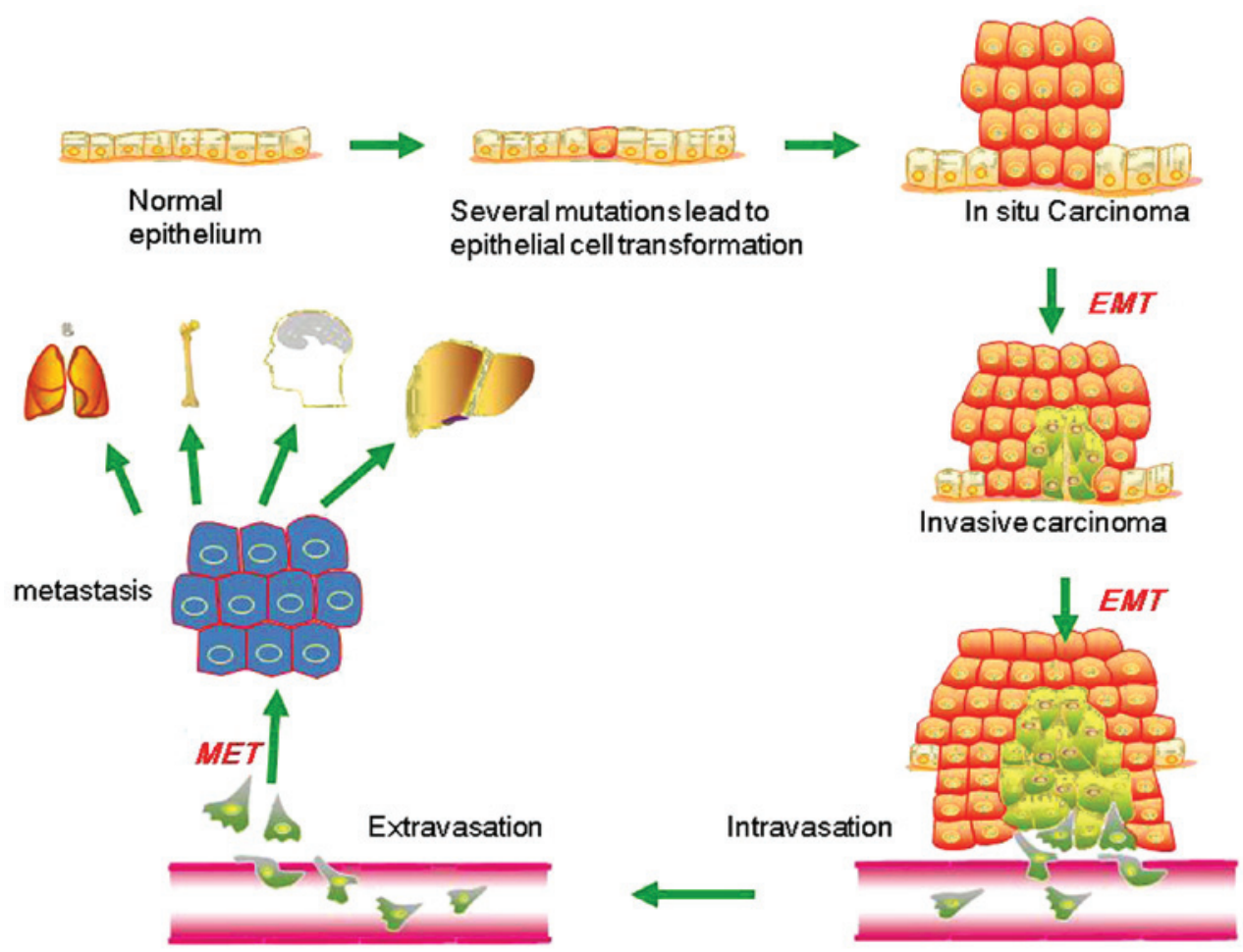

Figure 1. Putative EMT and MET in breast cancer progression. Normal epithelial cells undergo a series of transformational changes to become malignant tumor cells. Clonal proliferation of malignant cells gives rise to invasive carcinoma. Some of these cells undergo EMT and enter into the neighboring blood vessels or lymphatic vessels. These cells may remain in the circulation as circulating tumor cells or may extravasate at a distant site. The extravasated tumor cells form macrometastasis by a reverse mechanism known as MET. EMT, epithelial-mesenchymal transition; MET, mesenchymal-epithelial transition.

\section{Epithelial}

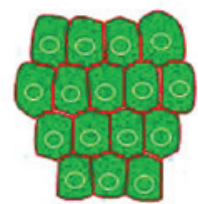

Tight cell contact, polarity maintained

$\mathrm{CD} 44 \mathrm{v}$

E-cadherin $\uparrow$

\section{Mesenchymal}

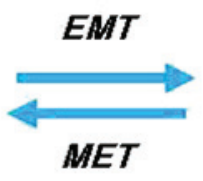

\section{Cell motility and invasive ability increase}

CD44s $\uparrow$
$N$-cadherin $\uparrow$
DDR2 $\uparrow$
$\beta-C a t e n i n \uparrow$
Vimentin $\uparrow$
$\alpha-S M A \uparrow$

Figure 2. EMT and MET. Epithelial cells display tight cell-cell contacts, maintain polarity and are not particularly motile, whereas mesenchymal-like cells are more motile and invasive. Proteins associated with the epithelial-like or the mesenchymal-like states are referred to as biomarkers. EMT, epithelial-mesenchymal transition; MET, mesenchymal-epithelial transition; CD, cluster of differentiation; v, variant isoform; s, standard isoform; DDR2, discoidin domain receptor 2; SMA, smooth muscle actin.

to EMT in embryogenesis and to wound healing in normal epithelial cells (41). In adults, significant $\alpha$-SMA expression can be found in vascular smooth muscle cells and myoepithelial cells (46). In cancer, evidence that the EMT is associated with $\alpha$-SMA is mostly confined to breast cancer (49), where
$\alpha$-SMA is largely detected in breast tumors of the 'basal phenotype' (50). A previous study used 60 patients with a known prognosis of invasive breast cancer to identify that $\alpha$-SMA and lymph node metastasis were independent predictive factors of metastasis. The result indicated that the metastasis group 
showed significantly higher $\alpha$-SMA expression compared with the non-metastasis group (51).

\section{EMT transcription factors in breast cancer}

The expression of E-cadherin plays a very important role in the process of EMT. EMT transcription factors can be classified based on their ability to repress E-cadherin directly or indirectly.

Direct inhibition of E-cadherin. The Snail family comprises three members, Snail 1, 2 and 3 (also termed Snail, Slug and Smuc, respectively). Snail 1 and 2 both repress the expression of the epithelial marker gene cadherin 1 (CDH1), which encodes E-cadherin. Snail-induced EMT is due to the direct repression of E-cadherin transcription. Snail is the most widely recognized suppressor of E-cadherin expression (52). Snail-induced EMT produces concerted biophysical changes due to altered cytoskeletal gene expression. Biophysical changes associated with cancer metastasis, including elevated traction forces and loss of cytoskeletal and nuclear structure, are directly induced by EMT in the absence of any extraneous environmental cues (53). Snail promotes EMT in breast cancer cells in part via activation of nuclear ERK2 (54). Furthermore, the overexpression of Snail in MCF-7 breast cancer cells induced EMT, increased cell migration, reduced cell adhesion and increased tumorigenicity (54). In addition, the second member of the Snail family, Slug, does play a major role during EMT. The metastatic spread of triple-negative breast cancer may be suppressed by blocking the Slug activity, which may specifically inhibit the homing/colonization to the bone (55). However, the third member of the Snail family, Smuc, does not play a major role during EMT (52).

The ZEB family (ZEB1/2) comprises zinc-finger transcription factors that recognize a consensus E-box type element, which are known as ZEB proteins (52). These proteins directly repress E-cadherin expression independently of Snail transcription factors in mouse mammary epithelial cells $(56,57)$. ZEB1 and/or ZEB2 expression increased aggressiveness and metastatic capacity in breast cancer (58). ZEB1 and ZEB2 not only repress E-cadherin but also other epithelial markers involved in cell polarity, components of tight junctions, gap junctions and desmosomes (59-61). Moreover, ZEB1 plays an important role in tumor progression and poor clinical outcomes in cancer patients. It is an specific EMT inducer that dictates cancer stem cell properties, such as radioresistance and drug resistance (62). ZEB2 directly represses the expression of the tight junction proteins claudin-4 and zona occludens 3 (61). It also suppresses the expression of the desmosome protein plakophilin-2, and induces the expression of the mesenchymal proteins vimentin, $\mathrm{N}$-cadherin and matrix metalloproteinase- 2 through a yet unknown mechanism (61). It has been reported that cytoplasmic ZEB2 is an important factor in the early stages of malignancy, and it also predicts a poor overall survival rate in invasive micropapillary carcinoma in a canine mammary cancer model (58).

The members of the basic helix-loop-helix family (Twist-1/2) are homodimers or heterodimers that can bind to a consensus E-box sequence (63). Their expression is upregulated during early embryonic morphogenesis, tissue fibrosis and cancer metastasis (64-66). Overexpression of Twist produced a transformation of the MCF-7 cell line that exhibited many of the traits representative of an epithelial-mesenchymal-like transition (67). In addition, we also reported that Twist was able to upregulate vascular endothelial growth factor (VEGF) synthesis and to induce in vivo angiogenesis (67). Expression of Twist-1 is associated with poor survival in carcinoma. However, the potential of Twist-1 as a therapeutic target in cancer treatment still requires validation in further research (68).

Indirect inhibition of E-cadherin. The other group of CDH1 repressors (indirect regulators) comprises Forkhead box protein $\mathrm{C} 2$ (FoxC2), goosecoid, TCF4 and X-box binding protein 1 (XBP1) (69-72). FoxC2 is a winged helix/forkhead domain transcription factor that acts as a pleiotropic inducer of EMT. FoxC2 is expressed in ductal breast cancers and metastatic breast cancer cell lines (69). Elevated levels of FoxC2 protein were associated with the basal-like breast cancer phenotype and with a poor rate of disease-free survival (73). In addition, expression of FoxC2 and co-expression of Twist and FoxC2 in the stroma of breast phyllodes tumors contributed to poorer prognosis (74). The goosecoid homeobox transcription factor is overexpressed in the majority of human breast tumors. Ectopic expression of goosecoid in human breast cells caused invasion-associated cellular changes, including EMT. Moreover, goosecoid significantly enhanced the ability of breast cancer cells to form pulmonary metastases in mice (75). TCF4 belongs to the $\beta$-catenin pathway, and is one of the ZEB family transcription factors. TCF-4-regulated osteopontin (OPN) expression and cell invasion may be dependent on Wnt signaling activity, and TCF-4 and OPN may become a novel prognostic indicator in breast cancer when considered together (71). Moreover, XBP1 is an important transcription factor within the cAMP response element binding protein/activating transcription factor family, and it contains a basic leucine zipper structure (72). It has been reported that the forced expression of XBP1 induces EMT in breast cancer cells. The authors specified that XBP1 decreases the expression of the epithelial marker E-cadherin but increases the expression of the mesenchymal markers $\mathrm{N}$-cadherin and vimentin. These results indicated that XBP1 induces EMT and cell invasion in breast cancer cells by promoting Snail expression (72).

\section{EMT-related miRNAs in breast cancer}

miRNAs, functioning as co-activators or co-repressors, are key players in cell plasticity, being specifically involved in cell regulation with EMT-related transcription factors. miRNAs that contribute to EMT in breast cancer are categorized as either EMT inducers or EMT repressors (Table I).

miRNAs with EMT-inducer activities. The well-known oncomiR miR-21 was identified as an EMT inducer, while phosphatase and tensin homolog (PTEN) is a major miR-21 target that negatively regulates EMT phenotypes (76). The antagonism of miR-21 in the MDA-MB-231 aggressive breast cancer cell line is found to reverse EMT, which is accompanied by PTEN upregulation and AKT/ERK1/2 inactivation (77). That study suggests that miR-21 functions as an oncogene and 
Table I. EMT-related miRNAs in breast cancer.

\begin{tabular}{lccc}
\hline miRNA identity & Target(s) & Role of EMT & References \\
\hline miR-21 & PTEN & Inducer & $(57,58)$ \\
miR-10b & HOXD10 & Inducer & $(59,60)$ \\
miR-9 & CDH1 & Inducer \\
miR-103/107 & Dicer1 & Inducer \\
miR-200 family & ZEB1, ZEB2 & Repressor \\
miR-375 & SHOX2 & Repressor \\
miR-506 & Slug & Repressor \\
miR-203 & Snail, Slug & Repressor \\
miR-34 & Snail & Repressor \\
\hline
\end{tabular}

EMT, epithelial-mesenchymal transition; miR/miRNA, microRNA; PTEN, phosphatase and tensin homolog; HOXD10, homeobox D10; $\mathrm{CDH} 1$, cadherin 1; ZEB, zinc finger E-box binding homeobox; SHOX2, short stature homeobox 2.

modulates tumorigenesis, and it may serve as a novel therapeutic target.

miR-10b was identified as a positive regulator of EMT, and it was demonstrated to be a positive effector of Twist. It was shown to induce migration and invasion capacities in breast cancer cells via direct targeting of homeobox D10 (HOXD10) transcription (78). miR-10b-mediated suppression of HOXD10 has also been shown to promote the expression of Ras homolog family member $\mathrm{C}$, which leads to cell invasion and migration in the non-metastatic breast cancer cell line SUM149. Moreover, downregulation of miR-10b reduces the metastatic burden of breast cancer in vivo (79).

miR-9 is upregulated in breast cancer cells, and directly targets $\mathrm{CDH} 1$, leading to increased cell motility and invasiveness (80). Downregulation of miR-9-mediated E-cadherin expression results in the activation of $\beta$-catenin signaling, which contributes to the upregulation of VEGF; in turn, this leads to increased tumor angiogenesis (80). Overexpression of miR-9 is also found in tumors with aggressive phenotypes, and is related to poor prognosis in breast cancer, suggesting that it may serve as a potential biomarker for the progression of breast cancer as well as a target for treatment (81).

miR-103/107 inhibit the expression of Dicer, causing global miRNA downregulation. In breast cancer, high levels of miR-103/107 are associated with metastasis and poor outcome. miR-103/107 confer migratory capacities in vitro and empower metastatic dissemination of otherwise non-aggressive cells in vivo (82). Inhibition of miR-103/107 prevents migration and metastasis of malignant cells.

miRNAs with EMT-repressor activities. The miR-200 family members (miR-200a, miR- 200b, miR-200c, miR-141 and miR-429) were identified as the guardians of the epithelial phenotype in breast cancer (83). The miR-200 family activates the Sec23a-mediated tumor cell secretome, which leads to the secretion of metastasis-suppressive proteins (84). Predictably, loss of miRNA-200a is frequently observed in breast cancer, but this loss does not predict tumor recurrence or patient survival (85). miR-200 family members are encoded from two clusters, and directly target the messenger RNAs of the E-cadherin transcriptional repressors ZEB1 and ZEB2 (84).
Notably, Burk et al and other studies $(83,86)$ have shown that both promoter regions are repressed in mesenchymal cells by ZEB1 and ZEB2 through binding to a conserved pair of ZEB-type E-box elements. These studies established the existence of a double-negative feedback loop controlling ZEB1-ZEB2 and miR-200 family expression.

miR-375 is elevated in epithelial-like breast cancer cells, and ectopic miR-375 expression suppresses EMT in mesenchymal-like breast cancer cells. The authors identified short stature homeobox 2 (SHOX2) as a miR-375 target, and miR-375-mediated suppression in EMT was reversed by forced SHOX2 expression. This study reveals that the association between miR-375 and SHOX2 is a potent EMT regulator and plays a critical role in breast tumorigenicity (87).

miR-506, which is a novel miRNA, was found to be significantly related to breast cancer patient survival. It suppressed the expression of mesenchymal markers in the MDA-MB-231 human breast cancer cell line. In addition, nuclear factor- $\kappa \mathrm{B}(\mathrm{NF}-\kappa \mathrm{B})$ combines with the upstream promoter region of miR-506 to suppress transcription (87). It inhibited transforming growth factor (TGF)- $\beta$-induced EMT and suppressed adhesion, invasion and migration of MDA-MB-231 cells when miR-506 was overexpressed (88). In general, miR-506 plays a key role in the process of EMT via post-translational control of EMT-related genes.

During Snail-induced EMT in MCF7 breast cancer cells, miR-203 is repressed in a correlated manner. In particular, miR-203 represses endogenous Snail, forming a double-negative miR-203/Snail feedback loop (89). In addition, miR-203 is also able to target Slug. TGF- $\beta$ induces Slug to promote EMT by repressing the miR-203 promoter to inhibit its transcription. It was found that miR-203 is significantly downregulated in highly metastatic breast cancer cells, and that the restoration of miR-203 in these cells inhibits tumor cell invasion in vitro and lung metastatic colonization in vivo by repressing Slug (90).

miR-34 is one of the most studied tumor-suppressor miRNAs. It is implicated in the inhibition of EMT mediated by $\mathrm{p} 53$. It was reported that activation of p53 downregulates the EMT induced by the transcription factor Snail via induction of the miR-34 gene. Suppression of miR-34 caused upregulation 
of Snail and EMT markers, and enhanced cell migration and invasion. Moreover, miR-34a prevents TGF- $\beta$-induced EMT, and the repression of the miR-34 gene by Snail and related factors is part of the EMT program (91).

\section{EMT-related protein kinase in breast cancer}

Several kinases regulate EMT, stemness or metastasis, including FYN proto-oncogene, Src family tyrosine kinase, platelet-derived growth factor receptor $\alpha, \mathrm{BRAF}$, Fms-related tyrosine kinase 1, LYN proto-oncogene, Src family tyrosine kinase and YES proto-oncogene 1, Src family tyrosine kinase (92-94). In the present report, we review two recent studies on breast cancer occurrence and EMT-associated protein kinases.

AXL receptor tyrosine kinase (AXL) is a member of the Tyro3-AXL-Mer family of receptor tyrosine kinases. AXL is overexpressed in a wide variety of human cancers, with significant correlation with tumor stage in breast cancer patients. It plays a important role in cancer progression and metastasis (95-97). Asiedu et al (98) reported that AXL overexpression in HMLE cells downregulated E-cadherin, while the expression of mesenchymal markers such as $\mathrm{N}$-cadherin, Snail and Slug was upregulated. A similar result was observed by forced expression of AXL in the normal human mammary epithelial cell line MCF10A. On the contrary, the silencing of AXL by viral-mediated shRNA led to the upregulation of epithelial markers, while mesenchymal markers were downregulated. Inactivation of AXL also led to downregulation of the NF- $\mathrm{kB}$ pathway and reduced tumor formation in vivo (98). In addition, $\mathrm{AXL}$ is overexpressed in highly invasive breast cancer cell lines. By contrast, weakly invasive breast cancer cell lines do not or merely express limited quantities of AXL. AXL may be an important therapeutic target in inflammatory breast cancer (99).

CDKL2 is one of the most distant members of the cell division cycle protein 2-related serine/threonine protein kinase and mitogen-activated protein kinase family, which is also known as p56 or KKIAMRE $(100,101)$. A recent study $(100)$ demonstrated that CDKL2 activated a positive feedback loop, consisting of ZEB1/E-cadherin/ $\beta$-catenin, to induce EMT in breast cancer. As a result, E-cadherin expression was reduced, and the epithelial barrier was broken down, which led to nuclear translocation of $\beta$-catenin as well as elevated $\beta$-catenin/TCF4 transcriptional activity. Activated $\beta$-catenin increased ZEB1 promoter activity and transcription, which in turn resulted in further suppression of E-cadherin expression and continuous activation of the positive feedback loop (100) This result suggested that CDKL2 can be a potential prognostic factor for poor outcome and a therapeutic target for human invasive breast cancer.

\section{Conclusion}

Currently, the role of EMT and MET in breast tumors is under investigation, and the molecular mechanism of EMT and MET is being revealed. With the development of individualized breast cancer therapies, new prognostic and predictive biomarkers are required to facilitate clinical decision-making processes. Further studies on the link between
EMT markers and breast cancer, such as the link between EMT and biomarkers, the regulatory association between transcription factors and miRNAs, and the link between EMT and protein kinases, will contribute to the identification of biomarkers for predicting early breast cancer metastasis and to identify intervention therapeutic targets in breast cancer, as well as to provide new ideas and methods for the treatment of breast cancer.

\section{References}

1. Jemal A, Bray F, Center MM, Ferlay J, Ward E and Forman D: Global cancer statistics. CA Cancer J Clin 61: 69-90, 2011.

2. DeSantis C, Siegel R, Bandi P and Jemal A: Breast cancer statistics. CA Cancer J Cli 61: 409-418, 2011.

3. O'Shaughnessy J: Extending survival with chemotherapy in metastatic breast cancer. Oncologist 10 (Suppl 3): S20-S29, 2005.

4. Creighton CJ, Chang JC and Rosen JM: Epithelial-mesenchymal transition (EMT) in tumor-initiating cells and its clinical implications in breast cancer. J Mammary Gland Biol Neoplasia 15: 253-260, 2010.

5. Guarino M,Rubino B and Ballabio G: The role of epithelial-mesenchymal transition in cancer pathology. Pathology 39: 305-318, 2007.

6. Woodhouse EC, Chuaqui RF and Liotta LA: General mechanisms of metastasis. Cancer 80 (Suppl): 1529-1537, 1997.

7. Chambers AF, Groom AC and MacDonald IC: Dissemination and growth of cancer cells in metastatic sites. Nat Rev Cancer 2: 563-572, 2002

8. Weidner N, Folkman J, Pozza F, Bevilacqua P, Allred EN, Moore DH, Meli S and Gasparini G: Tumor angiogenesis: A new significant and independent prognostic indicator in early-stage breast carcinoma. J Natl Cancer Ins 84: 1875-1887, 1992.

9. Folkman J and Shing Y: Angiogenesis. J Biol chem 267: 10931-10934, 1992.

10. Folkman J: The role of angiogenesis in tumor growth. S Cancer Biol 3: 65-71, 1992.

11. Chao YL, Shepard CR and Wells A: Breast carcinoma cells re-express E-cadherin during mesenchymal to epithelial reverting transition. Mol Cancer 9: 179, 2010.

12. Chaffer CL, Brennan JP, Slavin JL, Blick T, Thompson EW and Williams ED: Mesenchymal-to-epithelial transition facilitates bladder cancer metastasis: Role of fibroblast growth factor receptor-2. Cancer Res 66: 11271-11278, 2006.

13. Chaffer CL, Thompson EW and Williams ED: Mesenchymal to epithelial transition in development and disease. Cells Tissues Organs 185: 7-19, 2007.

14. Hugo H, Ackland ML, Blick T, Lawrence MG, Clements JA, Williams ED and Thompson EW: Epithelial-mesenchymal and mesenchymal-epithelial transitions in carcinoma progression. J Cell Physiol 213: 374-383, 2007.

15. Hyafil F, Babinet $\mathrm{C}$ and Jacob F: Cell-cell interactions in early embryogenesis: A molecular approach to the role of calcium. Cell 26: 447-454, 1981.

16. Cavallaro U and Christofori G: Cell adhesion and signalling by cadherins and Ig-CAMs in cancer. Nat Rev Cancer 4: 118-132, 2004.

17. Hay ED and Zuk A: Transformations between epithelium and mesenchyme: Normal, pathological, and experimentally induced. Am J Kidney Dis 26: 678-690, 1995.

18. Vleminckx K, Vakaet L Jr, Mareel M, Fiers W and van Roy F: Genetic manipulation of E-cadherin expression by epithelial tumor cells reveals an invasion suppressor role. Cell 66: 107-119, 1991.

19. Perl AK, Wilgenbus P, Dahl U, Semb H and Christofori G: A causal role for E-cadherin in the transition from adenoma to carcinoma. Nature 392: 190-193, 1998.

20. Canel M, Serrels A, Frame MC and Brunton VG: E-cadherin-integrin crosstalk in cancer invasion and metastasis. J Cell Sci 126: 393-401, 2013.

21. Heimann R, Lan F, McBride R and Hellman S: Separating favorable from unfavorable prognostic markers in breast cancer: The role of E-cadherin. Cancer Res 60: 298-304, 2000.

22. Hunt NC, Douglas-Jones AG, Jasani B, Morgan JM and Pignatelli M: Loss of E-cadherin expression associated with lymph node metastases in small breast carcinomas. Virchows Arch 430: 285-289, 1997. 
23. Oka H, Shiozaki $\mathrm{H}$, Kobayashi K, Inoue $\mathrm{M}$, Tahara $\mathrm{H}$ Kobayashi T, Takatsuka Y, Matsuyoshi N, Hirano S and Takeichi M: Expression of E-cadherin cell adhesion molecules in human breast cancer tissues and its relationship to metastasis Cancer Res 53: 1696-1701, 1993.

24. Siitonen SM, Kononen JT, Helin HJ, Rantala IS, Holli KA and Isola JJ: Reduced E-cadherin expression is associated with invasiveness and unfavorable prognosis in breast cancer. Am J Clin Pathol 105: 394-402, 1996

25. Mahler-Araujo B, Savage K, Parry S and Reis-Filho JS: Reduction of E-cadherin expression is associated with non-lobular breast carcinomas of basal-like and triple negative phenotype. J Clin Pathol 61: 615-620, 2008

26. Lopes N, Carvalho J, Durães C, Sousa B, Gomes M, Costa JL, Oliveira C, Paredes J and Schmitt F: 1Alpha, 25-dihydroxyvitamin D3 induces de novo E-cadherin expression in triple-negative breast cancer cells by CDH1-promoter demethylation. Anticancer Res 32: 249-257, 2012.

27. Choi Y, Lee HJ, Jang MH, Gwak JM, Lee KS, Kim EJ, Kim HJ, Lee HE and Park SY: Epithelial-mesenchymal transition increases during the progression of in situ to invasive basal-like breast cancer. Hum Pathol 44: 2581-2589, 2013.

28. Gravdal K, Halvorsen OJ, Haukaas SA and Akslen LA: A switch from $\mathrm{E}$-cadherin to $\mathrm{N}$-cadherin expression indicates epithelial to mesenchymal transition and is of strong and independent importance for the progress of prostate cancer. Clin Cancer Res 13: 7003-7011, 2007.

29. Chao Y, Wu Q, Acquafondata M, Dhir R and Wells A: Partial mesenchymal to epithelial reverting transition in breast and prostate cancer metastases. Cancer Microenviron: 5: 19-28, 2012.

30. Brown RL, Reinke LM, Damerow MS, Perez D, Chodosh LA, Yang J and Cheng C: CD44 splice isoform switching in human and mouse epithelium is essential for epithelial-mesenchymal transition and breast cancer progression. J Clin Invest 121: 1064-1074, 2011

31. Leth-Larsen R, Lund R, Hansen HV, Laenkholm AV, Tarin D, Jensen ON and Ditzel HJ: Metastasis-related plasma membrane proteins of human breast cancer cells identified by comparative quantitative mass spectrometry. Mol Cell Proteomics 8: 1436-1449, 2009

32. Vogel W, Gish GD, Alves F and Pawson T: The discoidin domain receptor tyrosine kinases are activated by collagen. Mol Cell 1: 13-23, 1997.

33. Zeisberg EM, Tarnavski O, Zeisberg M, Dorfman AL, McMullen JR, Gustafsson E, Chandraker A, Yuan X, Pu WT, Roberts $\mathrm{AB}$, et al: Endothelial-to-mesenchymal transition contributes to cardiac fibrosis. Nat Med 13: 952-961, 2007.

34. Goldsmith EC, Hoffman A, Morales MO, Potts JD, Price RL, McFadden A, Rice M and Borg TK: Organization of fibroblasts in the heart. Dev Dyn 230: 787-794, 2004.

35. Yan Z, Jin S, Wei Z, Huilian H, Zhanhai Y, Yue T, Juan L, Jing L, Libo $Y$ and $\mathrm{Xu}$ L: Discoidin domain receptor 2 facilitates prostate cancer bone metastasis via regulating parathyroid hormone-related protein. Biochim Biophys Acta 1842: $1350-1363,2014$

36. Evtimova V, Zeillinger R and Weidle UH: Identification of genes associated with the invasive status of human mammary carcinoma cell lines by transcriptional profiling. Tumor Biol 24 : 189-198, 2003

37. Zhang K, Corsa CA, Ponik SM, Prior JL, Piwnica-Worms D, Eliceiri KW, Keely PJ and Longmore GD: The collagen receptor discoidin domain receptor 2 stabilizes SNAIL1 to facilitate breast cancer metastasis. Nat Cell Biol 15: 677-687, 2013.

38. Ren T, Zhang W, Liu X, Zhao H, Zhang J, Zhang J, Li X, Zhang Y, $\mathrm{Bu} \mathrm{X}$, Shi M, et al: Discoidin domain receptor 2 (DDR2) promotes breast cancer cell metastasis and the mechanism implicates epithelial-mesenchymal transition programme under hypoxia. J Pathol 234: 526-537, 2014.

39. Bienz M: beta-Catenin: A pivot between cell adhesion and Wnt signalling. Curr Biol 15: R64-R67, 2005.

40. Brabletz T, Jung A, Hermann K, Günther K, Hohenberger W and Kirchner T: Nuclear overexpression of the oncoprotein beta-catenin in colorectal cancer is localized predominantly at the invasion front. Pathol Res Pract 194: 701-704, 1998.

41. Zeisberg M and Neilson EG: Biomarkers for epithelial-mesenchymal transitions. J Clin Invest 119: 1429-1437, 2009.

42. Prasad CP, Rath G, Mathur S, Bhatnagar D, Parshad R and Ralhan R: Expression analysis of E-cadherin, Slug and GSK3beta in invasive ductal carcinoma of breast. BMC Cancer 9: 325, 2009.
43. Li L, Liu C, Amato RJ, Chang JT, Du G and Li W: CDKL2 promotes epithelial-mesenchymal transition and breast cancer progression. Oncotarget 5: 10840-10853, 2014.

44. Scanlon CS, Van Tubergen EA, Inglehart RC and D'Silva NJ: Biomarkers of epithelial-mesenchymal transition in squamous cell carcinoma. J Dent Res 92: 114-121, 2013.

45. Raymond WA and Leong AS: Vimentin - a new prognostic parameter in breast carcinoma? J Pathol 158: 107-114, 1989.

46. Bindels S, Mestdagt M, Vandewalle C, Jacobs N, Volders L, Noël A, van Roy F, Berx G, Foidart JM and Gilles C: Regulation of vimentin by SIP1 in human epithelial breast tumor cells. Oncogene 25: 4975-4985, 2006.

47. Patel NA, Patel PS and Vora HH: Role of PRL-3, Snail, Cytokeratin and Vimentin expression in epithelial mesenchymal transition in breast carcinoma. Breast Dis 35: 113-127, 2015.

48. Gabbiani G, Kapanci Y, Barazzone P and Franke WW: Immunochemical identification of intermediate-sized filaments in human neoplastic cells. A diagnostic aid for the surgical pathologist. Am J Pathol 104: 206-216, 1981

49. Damonte P, Gregg JP, Borowsky AD, Keister BA and Cardiff RD: EMT tumorigenesis in the mouse mammary gland. Lab Invest 87 1218-1226, 2007

50. Sarrió D, Rodriguez-Pinilla SM, Hardisson D, Cano A, Moreno-Bueno G and Palacios J: Epithelial-mesenchymal transition in breast cancer relates to the basal-like phenotype. Cancer Res 68: 989-997, 2008.

51. Yamashita M, Ogawa T, Zhang X, Hanamura N, Kashikura Y, Takamura M, Yoneda $M$ and Shiraishi T: Role of stromal myofibroblasts in invasive breast cancer: Stromal expression of alpha-smooth muscle actin correlates with worse clinical outcome. Breast Cancer 19: 170-176, 2012.

52. Barrallo-Gimeno A and Nieto MA: The Snail genes as inducers of cell movement and survival: Implications in development and cancer. Development 132: 3151-3161, 2005.

53. McGrail DJ, Mezencev R, Kieu QM, McDonald JF and Dawson MR: SNAIL-induced epithelial-to-mesenchymal transition produces concerted biophysical changes from altered cytoskeletal gene expression. FASEB 29: 1280-1289, 2015.

54. Smith BN, Burton LJ, Henderson V, Randle DD, Morton DJ, Smith BA, Taliaferro-Smith L, Nagappan P, Yates C, Zayzafoon $\mathrm{M}$ et al: Snail promotes epithelial mesenchymal transition in breast cancer cells in part via activation of nuclear ERK2. PloS One 9: e104987, 2014

55. Ferrari-Amorotti G, Chiodoni C, Shen F, Cattelani S, Soliera AR, Manzotti G, Grisendi G, Dominici M, Rivasi F, Colombo MP et al: Suppression of invasion and metastasis of triple-negative breast cancer lines by pharmacological or genetic inhibition of slug activity. Neoplasia 16: 1047-1058, 2014.

56. Eger A, Aigner K, Sonderegger S, Dampier B, Oehler S, Schreiber M, Berx G, Cano A, Beug H and Foisner R: DeltaEF1 is a transcriptional repressor of E-cadherin and regulates epithelial plasticity in breast cancer cells. Oncogene 24: 2375-2385, 2005.

57. Shirakihara T, Saitoh M and Miyazono K: Differential regulation of epithelial and mesenchymal markers by deltaEF1 proteins in epithelial mesenchymal transition induced by TGF-beta. Mol Biol Cell 18: 3533-3544, 2007.

58. Gamba CO, Campos LC, Negreiros-Lima GL, Maciel-Lima K, Sousa LP, Estrela-Lima A, Ferreira E and Cassali GD: ZEB2 and ZEB1 expression in a spontaneous canine model of invasive micropapillary carcinoma of the mammary gland. Res Vet Sci 97: 554-559, 2014

59. Aigner K, Dampier B, Descovich L, Mikula M, Sultan A, Schreiber M, Mikulits W, Brabletz T, Strand D, Obrist P, et al: The transcription factor ZEB1 (deltaEF1) promotes tumor cell dedifferentiation by repressing master regulators of epithelial polarity. Oncogene 26: 6979-6988, 2007.

60. Aigner K, Descovich L, Mikula M, Sultan A, Dampier B, Bonné S, van Roy F, Mikulits W, Schreiber M, Brabletz T, et al: The transcription factor ZEB1 (deltaEF1) represses Plakophilin 3 during human cancer progression. FEBS Lett 581: 1617-1624, 2007.

61. Vandewalle C, Comijn J, De Craene B, Vermassen P, Bruyneel E, Andersen H, Tulchinsky E, Van Roy F and Berx G: SIP1/ZEB2 induces EMT by repressing genes of different epithelial cell-cell junctions. Nucleic Acids Res 33: 6566-6578, 2005.

62. Zhang P, Sun Y and Ma L: ZEB1: At the crossroads of epithelial-mesenchymal transition, metastasis and therapy resistance. Cell Cycle 14: 481-487, 2015

63. Moyret-Lalle C, Ruiz E and Puisieux A: Epithelial-mesenchymal transition transcription factors and miRNAs: 'Plastic surgeons' of breast cancer. World J Clin Oncol 5: 311-322, 2014 
64. Yu W, Kamara H and Svoboda KK: The role of twist during palate development. Dev Dyn 237: 2716-2725, 2008.

65. Kida Y, Asahina K, Teraoka H, Gitelman I and Sato T: Twist relates to tubular epithelial-mesenchymal transition and interstitial fibrogenesis in the obstructed kidney. J Histochem Cytochem 55: 661-673, 2007.

66. Yang MH, Wu MZ, Chiou SH, Chen PM, Chang SY, Liu CJ, Teng SC and Wu KJ: Direct regulation of TWIST by HIF-1alpha promotes metastasis. Nat Cell Biol 10: 295-305, 2008.

67. Mironchik Y, Winnard PT Jr, Vesuna F, Kato Y, Wildes F, Pathak AP, Kominsky S, Artemov D, Bhujwalla Z, Van Diest $P$, et al: Twist overexpression induces in vivo angiogenesis and correlates with chromosomal instability in breast cancer. Cancer Res 65: 10801-10809, 2005.

68. Wushou A, Hou J, Zhao YJ and Shao ZM: Twist-1 up-regulation in carcinoma correlates to poor survival. Int J Mol Sci 15: 21621-21630, 2014.

69. Mani SA, Yang J, Brooks M, Schwaninger G, Zhou A, Miura N, Kutok JL, Hartwell K, Richardson AL and Weinberg RA: Mesenchyme Forkhead 1 (FOXC2) plays a key role in metastasis and is associated with aggressive basal-like breast cancers. Proc Natl Acad Sci USA 104: 10069-10074, 2007.

70. Taube JH, Herschkowitz JI, Komurov K, et al: Core epithelial-to-mesenchymal transition interactome gene-expression signature is associated with claudin-low and metaplastic breast cancer subtypes. Proceedings of the National Academy of Sciences of the United States of America 107: 15449-15454, 2010

71.Ravindranath A, Yuen HF, Chan KK, Grills C, Fennell DA Lappin TR and El-Tanani M: Wnt- $\beta$-catenin-Tef- 4 signalling-modulated invasiveness is dependent on osteopontin expression in breast cancer. Br J Cancer 105: 542-551, 2011.

72.Li H, Chen X, Gao Y, Wu J, Zeng F and Song F: XBP1 induces snail expression to promote epithelial- to-mesenchymal transition and invasion of breast cancer cells. Cell Signal 27: 82-89, 2015

73. Li Y, Yang W, Yang Q and Zhou S: Nuclear localization of GLI1 and elevated expression of FOXC2 in breast cancer is associated with the basal-like phenotype. Histol Histopathol 27: 475-484, 2012.

74.Lim JC, Koh VC, Tan JS, Tan WJ, Thike AA and Tan PH: Prognostic significance of epithelial-mesenchymal transition proteins Twist and Foxc2 in phyllodes tumors of the breast. Breast Cancer Res Treat 150: 19-29, 2015.

75. Hartwell KA, Muir B, Reinhardt F, Carpenter AE, Sgroi DC and Weinberg RA: The Spemann organizer gene, Goosecoid, promotes tumor metastasis. Proc Natl Acad Sci USA 103: 18969-18974, 2006

76. Si ML, Zhu S, Wu H, Lu Z, Wu F and Mo YY: miR-21-mediated tumor growth. Oncogene 26: 2799-2803, 2007.

77. Han M, Liu M, Wang Y, Chen X, Xu J, Sun Y,Zhao L, Qu H,Fan Y and Wu C: Antagonism of miR-21 reverses epithelial-mesenchymal transition and cancer stem cell phenotype through AKT/ERK1/2 inactivation by targeting PTEN. PloS One 7: e39520, 2012.

78. Harquail J, Benzina S and Robichaud GA: MicroRNAs and breast cancer malignancy: An overview of miRNA-regulated cancer processes leading to metastasis. Cancer Biomark 11: 269-280, 2012.

79. Ma L, Reinhardt F, Pan E, Soutschek J, Bhat B, Marcusson EG, Teruya-Feldstein J, Bell GW and Weinberg RA: Therapeutic silencing of miR-10b inhibits metastasis in a mouse mammary tumor model. Nat Biotechnol 28: 341-347, 2010.

80. Ma L, Young J, Prabhala H, Pan E, Mestdagh P, Muth D, Teruya-Feldstein J, Reinhardt F, Onder TT, Valastyan S, et al miR-9, a MYC/MYCN-activated microRNA,regulates E-cadherin and cancer metastasis. Nat Cell Biol 12: 247-256, 2010.

81. Gwak JM, Kim HJ, Kim EJ, Chung YR, Yun S, Seo AN, Lee HJ and Park SY: MicroRNA-9 is associated with epithelial-mesenchymal transition, breast cancer stem cell phenotype and tumor progression in breast cancer. Breast Cancer Res Treat 147: 39-49, 2014

82. Martello G, Rosato A, Ferrari F, Manfrin A, Cordenonsi M, Dupont S, Enzo E, Guzzardo V, Rondina M, Spruce T, et al: A MicroRNA targeting dicer for metastasis control. Cell 141: 1195-1207, 2010.
83. Burk U, Schubert J, Wellner U, Schmalhofer O, Vincan E, Spaderna $S$ and Brabletz T: A reciprocal repression between ZEB1 and members of the miR-200 family promotes EMT and invasion in cancer cells. EMBO Rep 9: 582-589, 2008.

84. Korpal M, Ell BJ, Buffa FM, Ibrahim T, Blanco MA, Celià-Terrassa $\mathrm{T}$, Mercatali L, Khan Z, Goodarzi H, Hua Y, et al: Direct targeting of Sec23a by miR-200s influences cancer cell secretome and promotes metastatic colonization. Nat Med 17: 1101-1108, 2011

85. Jang K, Ahn H, Sim J, Han H, Abdul R, Paik SS, Chung MS and Jang SJ: Loss of microRNA-200a expression correlates with tumor progression in breast cancer. Transl Res 163: 242-251, 2014.

86. Bracken CP, Gregory PA, Kolesnikoff N, Bert AG, Wang J, Shannon MF and Goodall GJ: A double-negative feedback loop between ZEB1-SIP1 and the microRNA-200 family regulates epithelial-mesenchymal transition. Cancer Res 68: 7846-7854, 2008.

87. Hong S, Noh H, Teng Y, Shao J, Rehmani H, Ding HF, Dong Z, Su SB, Shi H, Kim J and Huang S: SHOX2 is a direct miR-375 target and a novel epithelial-to-mesenchymal transition inducer in breast cancer cells. Neoplasia 16: 279-290.e1-5, 2014

88. Arora H, Qureshi R and Park WY: Mir-506 regulates epithelial mesenchymal transition in breast cancer cell lines. PloS One 8 : e64273, 2013

89. Moes M, Le Bechec A, Crespo I, Laurini C, Halavatyi A, Vetter G, Del Sol A and Friederich E: A novel network integrating a miRNA-203/SNAI1 feedback loop which regulates epithelial to mesenchymal transition. PloS One 7: e35440, 2012.

90. Ding X, Park SI, McCauley LK and Wang CY: Signaling between transforming growth factor $\beta$ (TGF- $\beta$ ) and transcription factor SNAI2 represses expression of microRNA miR-203 to promote epithelial-mesenchymal transition and tumor metastasis. J Biol Chem 288: 10241-10253, 2013.

91. Siemens H, Jackstadt R, Hünten S, Kaller M, Menssen A, Götz U and Hermeking H: miR-34 and SNAIL form a double-negative feedback loop to regulate epithelial-mesenchymal transitions. Cell Cycle 10: 4256-4271, 2011

92. Saito YD, Jensen AR, Salgia R and Posadas EM: Fyn: A novel molecular target in cancer. Cancer 116: 1629-1637, 2010.

93. Jechlinger M, Sommer A, Moriggl R, Seither P, Kraut N, Capodiecci P, Donovan M, Cordon-Cardo C, Beug H and Grünert S: Autocrine PDGFR signaling promotes mammary cancer metastasis. J Clin Invest 116: 1561-1570, 2006.

94. Choi YL, Bocanegra M, Kwon MJ, Shin YK, Nam SJ, Yang JH, Kao J, Godwin AK and Pollack JR: LYN is a mediator of epithelial-mesenchymal transition and a target of dasatinib in breast cancer. Cancer Res 70: 2296-2306, 2010.

95. Hutterer M, Knyazev P, Abate A, Reschke M, Maier H, Stefanova N, Knyazeva T, Barbieri V, Reindl M, Muigg A, et al: Axl and growth arrest-specific gene 6 are frequently overexpressed in human gliomas and predict poor prognosis in patients with glioblastoma multiforme. Clin Cancer Res 14: 130-138, 2008

96. Li Y, Ye X, Tan C, Hongo JA, Zha J, Liu J, Kallop D, Ludlam MJ and Pei L: Axl as a potential therapeutic target in cancer: Role of Axl in tumor growth, metastasis and angiogenesis. Oncogene 28: 3442-3455, 2009.

97. Zhang YX, Knyazev PG, Cheburkin YV, Sharma K, Knyazev YP, Orfi L, Szabadkai I, Daub H, Kéri G and Ullrich A: AXL is a potential target for therapeutic intervention in breast cancer progression. Cancer Res 68: 1905-1915, 2008.

98. Asiedu MK, Beauchamp-Perez FD, Ingle JN, Behrens MD, Radisky DC and Knutson KL: AXL induces epithelial-to-mesenchymal transition and regulates the function of breast cancer stem cells. Oncogene 33: 1316-1324, 2014.

99. Wu X, Liu X, Koul S, Lee CY, Zhang Z and Halmos B: AXL kinase as a novel target for cancer therapy. Oncotarget 5: 9546-9563, 2014.

100. Taglienti CA, Wysk M and Davis RJ: Molecular cloning of the epidermal growth factor-stimulated protein kinase p56 KKIAMRE. Oncogene 13: 2563-2574, 1996.

101. Gomi H, Sun W, Finch CE, Itohara S, Yoshimi K and Thompson RF: Learning induces a CDC2-related protein kinase, KKIAMRE. J Neurosci 19: 9530-9537, 1999. 